\title{
Diachronic patterns of usage of no doubt in the English Historical Book Collection (EEBO, ECCO and EVANS)
}

\author{
Chris A. Smith \\ CRISCO EA4255, Université de Caen Normandie, France
}

\begin{abstract}
This study offers a collocate analysis of the modal marker no doubt (ND) in the EEBO, ECCO and EVANS combined corpora using Sketch Engine. The purpose is to determine the diachronic patterns of usage of ND, and secondly to compare results with the conclusions of existing diachronic pragmatic studies of modal markers. The first step identified five patterns of behaviour based on AM score in decreasing order of frequency: 1 - NDB (no doubt but); 2 TISND (there is no doubt); 3 - MND (make no doubt); 4 - (ND (parenthetical use); 5 - Ndont (no doubt on't). The second step consisting in partitioning of the corpus following Hilpert and Gries (2016) produced 3 distinct periods based on EHBO data (1580-1669, 1670-1759, 1760-1799). The findings showed that the relative usage of ND for each period remained remarkably consistent, especially the persistence of non-grammaticalized behaviours MND and TISN. The two major disparities, concerning NDont and parenthetical (ND, were shown to be of likely significance for the changing pragmatic behaviour of ND, which further diachronic study may be able to ascertain.
\end{abstract}

Key words: Sketch Engine; collocate analysis; diachronic corpus; grammaticalization; modal marker; EEBO; ECCO; EVANS.

\section{Introduction}

Modality and the expression of modality remain a long-standing area of linguistic inquiry. Much discussion around the definition and typology of modality still exists (de Haan, 2006), but suffice it to say, for the purpose of this introduction, that modality is a broad concept which refers to attitudinal qualifications that convey a speaker's stance towards what is being said (see Cornillie \& Pietranrdea, 2012) for an overview of the issues surrounding defining modality, strictly or broadly, and its relation to evidentiality in particular).

In terms of language evolution, there have been many attempts to identify the underlying causes of change, whether cognitive, biological or func- 
tional. Theories of language change, such as grammaticalization and subjectification, are taking on a central role, and the new-found focus on data and usage-based analysis, rather than abstract theoretical models, has been instrumental in providing insight into the phenomenon. Grammaticalization, occasionally referred to as bleaching, is described as a loss of lexical content, or, as Traugott (2003: 645) explains, a change in the level of functioning, i.e. "the process whereby lexical material in highly constrained pragmatic and morphosyntactic contexts is assigned grammatical function, and once grammatical, is assigned increasingly grammatical, operator-like function" (also see Traugott 2011, 2003). Insofar as this process is gradual, for some (Traugott \& Dasher, 2002; Traugott, 2003; Benitez-Burraco, 2017), the process is closely related to the theories of the evolution of language (Eckhart, 2002, 2003, 2011).

This study aims to gather evidence of the behaviour of the modal marker no doubt (ND) in English by means of a corpus-based collocate study in the EEBO, ECCO and EVANS combined corpora comprising 826 million words. Modality has long been studied in the context of grammaticalization (see Ziegeler, 2011), as has evidentiality (Aikhenvald, 2011), both from crosslinguistic and language-specific perspectives. Studies of specific markers have been carried out historically, such as the discourse markers well, oh, marry, pray (Jucker, 2002; Lutzky, 2012) and modal adverbs of "certainty" (Simon-Vandenberger, 2007), including the markers surely and no doubt (also see Traugott, 2011). However, the specificity of this study will be the collocate approach, which aims to measure the semantic relatedness of a structure with its significant collocates. The literature shows there is evidence that shifting collocational patterns can offer insight into historical semantic and distributional change (see Hilpert, 2011, 2012; Hilpert \& Gries, 2016).

This paper is organized as follows. Section 2 deals with the background on modality and diachrony, laying out the issues at stake for this study. Section 3 presents the corpus material, and justifies the method chosen to collect data on no doubt (ND) in the English Historical Book Collection corpus comprising data from the EEBO (English Historical Books Online), ECCO (Eighteenth Century Collections Online) and EVANS corpus (5007 books published in America 1639-1800). Section 4 then presents the findings and summarizes the patterns found to be significant using a collocate analysis of ND. From there, a careful discussion of timeline partitioning is proposed, pointing out the issues or confounding factors relating to a diachronic approach (Section 5). In Section 6, the findings regarding diachronic patterns are presented, including the discussion of their significance. Finally, a summary of the results and issues raised concludes this analysis (Section 7). 


\section{Background}

\subsection{The modal marker ND}

The lexico-grammatical structure ND is known to function today as an adverbial of certainty (Simon-Vandenberger \& Aijmer, 2007). To be more specific, it is frequently used as an adverbial modal marker expressing high degree of certainty, or even, seemingly paradoxically, of uncertainty. This adverbial usage of no doubt is viewed by some as a case of grammaticalization, in so far as no doubt has become a discourse marker of certainty. SimonVandenberger \& Aijmer (2007) suggest that the degree of certainty expressed has become weaker historically, resulting in an expression of probability rather than of certainty (Simon-Vandenberger \& Aijmer, 2007; Aijmer, 2002). Simon-Vandenberger \& Aijmer (2007: 127) propose the shift in usage of no doubt is due to shortening and grammaticalization of the expression no doubt about it, leading to subjectification and weakening. Simon-Vandenberger's (2007) diachronic syntagmatic analysis of adverbs of modal certainty based on the Helsinki corpus supports this hypothesis, showing three conclusions: (1) the existential use of no doubt (there is no doubt) pre-existed the adverb, (2) the semantic and pragmatic versatility has increased, and (3) no doubt has become a discourse marker.

Traugott (2011: 68) identifies doubt as a loanword from the French c 1300, originally meaning "to fear, dread" (as confirmed in the OED as a now obsolete sense of the verb doubt). ND was originally used in the structures It is no doubt / I have-make no doubt. According to Traugott (2011), the usage of ND as an adverbial can be dated back to 1400, with Right Periphery usage dating back to 1710 (which tends to encode intersubjectivity, but more on this later). Traugott (2011) uses The Corpus of Late Modern English Texts Extended Version or CLEMETEV (1710-1920) to study the adverbs surely and no doubt and their recruitment as epistemic linkers or stance-markers. Traugott places no doubt lower on the scale of certainty than surely (2011: 59). Her findings are that surely and no doubt differ in that ND remains in a subjective speakeroriented function, whereas surely tends to function with hearer-oriented interactional value. Traugott $(2011,2012,2014)$ finds that ND has subjective meaning both in left and right periphery distribution rather than taking on intersubjective functions.

For the methodology of this study, the question of which features encode subjectivity or intersubjectivity remains key, as does the question of whether change, especially micro-change, can be quantified, given the variables of period and text type, and on what scale. 


\subsection{How to track the features of grammaticalization}

There have been many attempts to define grammaticalization. Narrog \& Heine (2011) provide a comprehensive view, also Ziegeler (2011), Narrog (2017: 39) but it is generally accepted to be a diachronic dynamic process of semantic change (Hopper 1991). The main differences lie in the description of the parameters of change. For some, such as Nicolle (2011), grammaticalization is the shift in encoding of information from conceptual information (content) to procedural information (i.e. discourse-related). Recent empirical corpus-based and cross-linguistic work has refined the parameter-approach to grammaticalization proposed by Lehmann (2002). For Narrog (2017: 110) and Narrog \& Heine (2011), it is increasing speech act-orientation that is a key parameter of grammaticalization, that is an increase relative to the original meaning rather than an absolute increase. By determining that grammaticalization is a process, presenting various stages, it becomes clear that the process of grammaticalization is gradable and therefore cannot be identified by absolute parameters. Traugott \& Dasher (2002) and Traugott (2011) argue that the change of meaning in the grammaticalization process expresses increasing stance-taking and beliefs or intentions on the part of speaker (subjectification), and in some cases the addressee (intersubjectification). Narrog (2017: 42) argues that hearer-orientation may be associated with early stages of grammaticalization, whereas speaker and discourse orientation are linked to later stages of grammaticalization.

\subsection{Specificity of this study: collocate study and context}

The specificity of this study is applying a corpus collocate study to a lexicogrammatical structure. One of the main issues in studying and identifying behaviour of lexico-grammatical structures is what type of meaning we should seek to identify. Simon-Vandenberger \& Aijmer (2007: 54) suggest a division between the procedural and conceptual meaning of modal markers. This position is shared by Cornillie (2010: 300) who explains that "[. . .] a satisfactory account of modal adverbs not only examines their semantic (and pragmatic) meaning, but also deals with their interactional or procedural meaning".

[...] it is possible that [adverbs of certainty] have both 'contentful' and procedural meaning. An adverb has a specific evidential or epistemic modal meaning. We will refer to this as the conceptual meaning of the adverbs and distinguish it from the procedural meaning. For example, certainly is contentful in that it means epistemic certainty and procedural when looked upon from the perspective of indexing the speaker's or writer's stance to the text or one of the participants. (SimonVandenberger \& Aijmer, 2007: 54) 
For this corpus analysis, the question is also how much context should be considered to identify the contextual basis for meaning (see Hennemann (2012) who distinguishes between meaning aspects that are encoded and others that are contributed by the context). The argument for the textual function of modal markers is made by Cornillie \& Pietrandrea (2012), who suggest that the entire text is required for the analysis of patterns. In this study, taking into account a large portion of context is not feasible given the amount of data to be processed in the EHBO. However, these issues of context and the scope of pragmatic criteria, will be taken into consideration in our proposed method and analysis of the corpus data.

\section{Material and method}

\subsection{Objectives and assumptions of the collocate study of a lexi- cogrammatical structure}

From a corpus analysis perspective, the structure no doubt verifies the six features of collocates delineated in Gries (2015b: 136-137) listed as follows: 1Nature of the collocates (DET + N); 2- Number of collocates (2); 3- Frequency of combination; 4- Uninterruptability of collocates; 5- Degree of lexical flexibility of the collocates; 6- Semantic role played by unity and noncompositionality.

In this analysis, we seek to provide answers to some of the questions arising from the literature on modality, grammaticalization and language change, as well as methodological issues. Q1) If and how do the patterns of usage of ND in the EHBO evolve over time? How do we accurately determine patterns and their interpretation? Q2) What features signal increasing grammaticalization? Q3) How do the data compare with Simon-Vandenberger \& Aijmer's (2007) corpus-based study using ICE (International Corpus of English) and Traugott's findings on ND (2011, 2012, 2014)?

In order to provide answers to the questions posed by the relative complexity of no doubt (ND), this paper proposes a collocate analysis aiming to determine the behaviour of ND by analysing its collocates. The method is a traditional collocate study using association measures instead of raw frequencies, aiming to identify significant collocates to paint a picture of the semantic and syntactic behaviour of the structure (see Gries 2015b). Association measures calculate the statistical relevance of the co-occurrence (called an AM score), going beyond raw frequencies to assess how strong the bond is between the two terms. For this purpose, Sketch Engine (Kilgarriff et al, 2004) is used as a corpus management and analysis tool: Sketch Engine provides a highly performing corpus platform and query system which is par- 
ticularly well suited to distributional semantic study and sense discrimination.

Therefore, I will now proceed with the presentation of the corpus frequencies of ND in the combined EEBO/ECCO/EVANS corpus. In the next section, I consider the quantitative behaviour of ND by looking at the collocate patterns based on the relative significance of a co-occurrence of a collocate with a target word, the AM score.

\subsection{Frequency of combination of no + doubt in the English Historical Book Collection (EHBO)}

Before I begin with a quantitative analysis of ND, let us consider the corpus data for the English Historical Book Collection or EHBO (1473-1820). As mentioned previously, the corpus comprises the data from the EEBO, Early English Books Online, a collection of English books published between 1473 and 1820. It also comprises ECCO Eighteenth Century Collection Online, 2473 titles printed in the United Kingdom between the years 1701 and 1800, and the EVANS corpus based on 5007 books published in America during the years 1639-1800. The corpus contains over 800 million words and over 30,000 texts.

The EHBO therefore predates Traugott's CLEMETEV corpus (2011) in her study of no doubt and surely which focuses on 1710-1920. The data is exclusively written text, which presents a possible confounding factor for the analysis of historical pragmatics, an issue which will be considered in the discussion section of the findings. The sources are published texts, belonging to a variety of genres, such as Historical Narratives, Biblical texts, Sermons, Plays, Novels. The importance and relevance of the variety of genres will be addressed in the analysis and discussion sections.

Table 1: EHBO corpus data (provided by Sketch Engine).

\begin{tabular}{ll}
\hline Tokens & $987,242,247$ \\
Words & $826,296,048$ \\
Sentences & $388,835,778$ \\
Paragraphs & $10,172,107$ \\
Documents & 32,844 \\
\hline
\end{tabular}

An initial query for the noun doubt generates a total of 90,312 tokens, a frequency of 91.47 per million. The first question is how frequent is the colligation no doubt out of the other premodifier collocates of the noun doubt? Table 2 provides the raw frequency of usage of each form in column 2. Col- 
umn 3 provides the all-important AM, which uses the frequencies throughout the corpus to calculate the strength of the bond between the collocates. This means a frequent collocate may not actually be a significant collocate if it appears frequently in other associations. In table 2, the collocates of the noun doubt are ranked in descending order of significance (using logDice measure, one of the best performing association measures, as discussed in Rychlý, 2008).

Table 2: Top premodifiers of the noun doubt in EHBO ranked by logDice.

\begin{tabular}{lrc}
\hline-1 modifier position & Tokens & logDice AM \\
\hline past/ paft & $250 / 145$ & $8.39 / 8.05$ \\
least / leaft/ & $250 / 124$ & $7.18 / 7.01$ \\
No/Noe & $57 / 46$ & $6.8 / 6.41$ \\
reafonable & 69 & 6.48
\end{tabular}

It is worth noting that 1) no does not in fact rank first in the list of collocates according to association measure (AM) logDice, and 2) the concordance results are sensitive to spelling variations, such as capitalization or historical spelling variations, which explains why past, least and no have two separate entries (which I have proceeded to regroup in the table). The form no presents a spelling with capital $\mathrm{N}$ marking the beginning of a sentence, and noe, a spelling variation. According to OED3, noe (IOE) is a variant of none, "used originally before consonants except $\underline{h}$, which ultimately became the standard form for the negative determiner except in archaic or poetic use." Notably, there is no occurrence of no without a capital appearing in the ranking, as is shown in Table 2.

As mentioned above, past and least outperform no/noe in terms of their AM. They are found to be the top collocates in the premodifier position, in both modern and historical spellings, although modern spellings are found to be both more frequent and higher in AM score. As with No, least in the modern spelling does not appear in the collocate list without capitalization. No appears a close third in the ranking, with the third highest score, including spelling variation noe which is almost on a par with the modern spelling.

To clarify the presentation, I have included the variations in the table on the same line as the main word form, and I have indicated the tokens and scores for these variations in italics besides the main word form.

A closer inspection of the results for each collocate shows some errors in tagging, which have been removed from the table for clarity. For instance, least had an additional entry for the modern spelling least. The concordance 
data show that this is in fact an error, and that one of the least entries includes other collocates such as double, farther, further. Consequently, the relevant leaft category has 124 tokens, and the modern spelling least has 250 uses. The concordance for least doubt shows a high frequency of emphatic not in the least doubt, and other negative contexts such as without the least doubt. Other errors are easily spotted in the case of the lower scoring collocates wee (we doubt), nothing (I nothing doubt), way (in no way doubt), and none (no-one doubts. In all these cases, doubt is in fact a verb and not a noun. These false results have all been disregarded from Table 2 .

After this consideration of the overall significance of the no+doubt colligation, I will now investigate the collocates of no doubt itself in EHBO.

\subsection{Collocates of ND; left and right nodes}

A search for no doubt generates 32,739 tokens, i.e. a frequency of 33.2 per million. Table 3 shows the $-5+5$ range of collocates giving a guideline for refining the collocate search. This means the collocates can be found in the left and the right context within a range of 5 words of no doubt. The collocate candidates are ranked based on AM score logDice rather than raw frequency, which ensures an accurate assessment of the relative significance of the pairing target + collocate. Column 2 shows the total co-occurrence count of the collocate with the target expression ND, and column 3 provides the AM score.

Table 3: Collocate ranking for ND (case sensitive list).

\begin{tabular}{lcc} 
Collocates & Co-occurrence count & $\log$ Dice \\
\hline There & 1125 & 6.89 \\
there & 4851 & 6.49 \\
make & 2362 & 6.23 \\
but & 9090 & 6.18 \\
would & 2472 & 5.83 \\
Yes & 133 & 5.7 \\
entertained & 87 & 5.66 \\
will & 3093 & 5.57 \\
( & 3434 & 5.57 \\
) & 3004 & 5.38 \\
n't & 157 & 5.35 \\
yes & 51 & 5.09 \\
o & 169 & 4.68 \\
\hline
\end{tabular}


As previously mentioned, several collocate candidates appear separately with variations of spelling. As the search is case sensitive, There / there have two distinct entries, which both occur in the top two positions of the ranking. Yes / yes is another alternation that emerges, although the distinction is more significant insofar as the capitalized version is much higher ranked, suggestive of its use at the beginning of a sentence (or Left Periphery of the clause) as with $\mathrm{No} /$ no alternation.

It is interesting to note that punctuation signs are included in the collocate measure, and further that the use of brackets, both opening and closing brackets, is ranked very high on the list. This is a strong suggestion that no doubt occurs as a syntactic insert, as an extra-propositional comment, i.e. as a discourse marker.

Finally, a third observation concerns the collocate candidate $n^{\prime} t$. This segment is clearly not in fact a word, and can correspond to several uses, such as the negative clitic. On inspection of the concordance results, it appears the form $n^{\prime} t$ in question belongs to the form on't, presumably a contracted variation of on it (although it is worth pointing out that there are no instances of on it in the corpus in this position). It is an anaphoric proform, usually referring back to the preceding proposition as shown in (3a) or in (3b) in a probable cataphoric use (see examples in section 3.4). The concordance and tagging system separates $n^{\prime} t$ and $o$, which appears lower in the ranking as shown in table 3.

OED3 remarks that, before 1200, on was unstressed before a consonant and reduced to $o$, often coalescing with the following word. OED also notes that in the late $16^{\text {th }}$ to $18^{\text {th }}$ centuries, on was used colloquially and reduced to $o^{\prime}$ (see concordance (3a) and (3b) in section 3.4.). In addition, it can be noted at this stage, that only two are verbs in the collocates list, which both rank fairly high, although this is especially true of the verb make. These uses point to a typical lexical use of ND as event participant (make ND and entertain $N D)$. The significance of these seemingly lexical patterns remains to be discussed in the following section where the patterns are refined.

With the aim of determining the patterns of usage of $N D$ with more accuracy, the results from Table 3 can be refined using left and right node filters. This will provide a view of the distribution of the collocates and how they interact with the expression ND. A discussion of the significance of left context and right context for the usage of ND will follow the quantitative measurement.

\subsection{Collocates filtered to the right}

Table 4 provides the raw frequency of collocates in both +1 and +5 positions, as well as the AM scores for both positions. The position filter allows a com- 
parison to be established between collocates occurring directly after ND and those occurring with a range of 5 . This comparative view of the collocate positions allows us to establish which significant collocates occur closely in relation to ND. Some collocates such as continued for instance do not show relevant scores in close proximity with ND: continued can be disregarded here as it may be in significant association with another target word instead of ND.

Table 4: Collocates to the right of ND ranked by logDice association measure.

\begin{tabular}{lc|c|c|c}
\hline $\begin{array}{l}\text { Collocate } \\
\text { candidates }\end{array}$ & $\begin{array}{c}\text { Cooccurrence } \\
\text { count }+5\end{array}$ & $\begin{array}{c}\text { Cooccurrence } \\
\text { count }+1\end{array}$ & $\begin{array}{c}\text { LogDice } \\
+5\end{array}$ & $\begin{array}{c}\text { LogDice } \\
+1\end{array}$ \\
\hline but & 8721 & 5774 & 6.13 & 5.53 \\
n't & 152 & $\mathrm{X}$ & 5.3 & $\mathrm{X}$ \\
would & 1678 & 215 & 5.26 & 2.3 \\
) & 2449 & 1812 & 5.08 & 4.64 \\
continued & 133 & $\mathrm{X}$ & 5.06 & $\mathrm{X}$ \\
will & 2153 & 335 & 5.04 & 2.35 \\
\hline o & 164 & 151 & 4.63 & 4.52 \\
\hline
\end{tabular}

Four patterns emerge as significant, using the comparative association measures as a guideline. The contrast between the collocates occurring directly after $N D$ and those occurring within a range of 5 shows the greater affinity of some collocates of the closer collocates over the others. The ranking proposed here takes into consideration both $\mathrm{AM}$ for +1 and +5 position, which affects the ranking for some collocates, as previously mentioned. The collocates would and $\mathrm{on}^{\prime} t$ (which appears separately in the table as the tagging does not recognise the form as a single word) are both affected: would ranks rather low in the +1 position, suggesting it may not be as significantly correlated with ND. will exhibits a similar behaviour, albeit even less frequent than its tense-inflected counterpart would.

a) The conjunction but remains positioned first in ranking in all positions, indicating that ND but is by far the most significant pattern of usage.

b) The second significant pattern to emerge is parenthetical ND) with a closing parenthesis, occurring significantly in both ranges.

c) The third significant pattern is ND on't, with the +1 filter showing the occurrence of $o$, and the +5 showing the occurrence of $n^{\prime} t$. The concordance results show that these overlap as the cooccurrence counts are very close in values; 151 for $o+1,152$ for $n^{\prime} t+5$. The 
correlation of frequencies shows that $o n^{\prime} t$ is a pattern.

d) Finally, ND will and ND would occur in both ranges, although there is a drop in usage, indicating would tends to occur between +2 and +5 . Further investigation shows would is consistently ranked first before will.

How does each collocate pattern correlate with a pragmatic meaning? An investigation of the corpus concordance provides the following proposal. a) A concessive use for ND but; Traugott (2014) shows that ND is often used to mark stages of a reasoned argument as in (1); b) An insert or comment function with the closing bracket ND) as in (2); c) An emphatic focalized usage in ND on't; in 3a) an anaphoric use of ND with back reference to My mony is mine owne. To that extent ND on't has an emphatic use to prove a point. On't can be used as a complementizer to MND as in (3a), or as an insert comment in $(3 b)$ with what appears to be a cataphoric reference to the main predicate be better than hers; d) An irrealis or hypothetical usage, referring to epistemic probability in ND would or will. This is a core clausal use, accompanying a future tense, predicting truth values as in (4)

(1) But hereto we replie, that it is a thing necessarily required at our hands by God almighty, and therefore we must obiect no impossibilitie, especially whe our owne negligence, is the cause of all the difficultie, or if you will so call it, impossibilitie. We confesse it will be harde at the first, but we must doe our endeuour, and commit the successe vnto God, and there is no doubt but in time it will grow to an happy ende. [1584]

(2) I heard it affirmed by a Man, that was a great Dealer in Secrets, but Conspiracy (which himselfe hindred,) to haue killed Queene Mary, Sister to Queene Elizabeth, by BurningGlasse, when shee walked in Saint Iames Parke, from the Leads of the House. But thus much (no doubt) is true; That if Burning-Glasses could be brought to a great strength, (as they talke generally of Burning-Glasses, that are able to burne a Nauy,) the Percussion of the Aire alone, by such a Burning-Glasse, would make no Noise; No more than is found in Cornscations, and Lightnings, without Thunders. [1627]

(3a) $</ p>$ Nor bonds nor fetters Captaine, My mony is mine owne, I make no doubt on't. (1640) EModE

(3b) Man enters into Articles very readily before Marriage, and Jo he may, for he performs no more of them afterwards than he thinks fit. A Wife muft never difpute with her Husband, his Reafons are now no doubt on't better than hers, whatever they were before; he is fure to perfwade her out of her Agreement, and bring her, it muft be fuppos'd, Willingly [1700]

(4) If they reiect them, then let them boldely pronounce them accurfed: $\mathcal{E}$ if they prefume fo bolde an enterprife, then will the common people crie out againft them. This beinge done the trueth after fuch triall no doubt will 
preuayle. If they reiect not the auncient fathers the let vs alleadge theyr workes and wrytinges and confirme the matter in controuerfie out of them. [1577]

The same approach will now be applied to the left collocates of ND with a view to gathering a more global view of collocate behaviour to the left and to the right of ND.

\subsection{Collocates to the left -5 and -1}

The same comparative process is applied to filter left collocates of no doubt, with the aim of determining the combined significant patterns, and presented in Table 5. The ranking of collocates is compared based on distribution range: on the one hand, collocates occurring with a range of 5 words to the left of the target, and collocates occurring within a range of 1 before the target. The use of XX signals no such cooccurrence in the data. It is assumed here that collocates closest to the target ND are have stronger ties to the target, as less interference from other target words is likely.

Table 5: Left side collocates -5 and -1 positions.

\begin{tabular}{lccccc}
\hline Collocates & $\begin{array}{c}\text { Cooccurrence } \\
\text { count }-5\end{array}$ & $\begin{array}{c}\text { Cooccurrence } \\
\text { count - }\end{array}$ & LogDice -5 & LogDice -1 \\
\hline There & 1117 & $\mathrm{Xx}$ & 6.88 & $\mathrm{Xx}$ \\
there & 4159 & $\mathrm{Xx}$ & 6.26 & $\mathrm{Xx}$ \\
make & 2148 & 2071 & 6.09 & 6.04 \\
Yes & 123 & 44 & 5.58 & 4.1 \\
( & 2947 & 1885 & 5.34 & 4.7 \\
yes & 47 & $\mathrm{Xx}$ & 4.97 & $\mathrm{Xx}$ \\
admits & 34 & $\mathrm{Xx}$ & 4.69 & $\mathrm{Xx}$ \\
\hline
\end{tabular}

From these data, the following left node patterns of ND emerge

a) There is ND: there is by far the highest ranking in the -5 range, although it does not appear in the -1 range since is emerges in this position.

b) make ND: Make is by far the strongest candidate for the -1 position.

c) The use of an opening bracket to the left, (no doubt, shows it appears significantly both directly before the expression, or within a range of 5 words.

d) Yes ND, with the capitalized form, indicating first word of the sentence, inferring expectation of the reader/co-speaker's stance. 
The interpretation of the patterns based on the corpus results suggest the following pragmatic usage.

a) TIND: emphatic use of high probability. Forceful stance-taking. (Traugott (2014) calls this fore-closure as in (1) where TIND is complementized by BUT; or in (5) by BUT THAT or (5b) OF IT or [5c] THAT

b) MND: emphatic use of high probability and argumentative/ possibly evidential (argumentative) in (6) MND THAT; (6b) MND of; and (6c) MND BUT

c) (ND insert comment function of weaker certainty (which Prince et al. (1982) call a "shielding" / certainty marker) in (7) (ND) and in (7b) (use of ND initially)

d) YES ND: argumentative rhetorical use indicative of expectation of reaction, possibly concessive.

(5) Therefore, it were a Meere Fallacie and Mistaking, to ascribe that to the Force of Imagination, opon another Body, which is but the Force of Imagination vpon the Proper Body: For there is no doubt, but that Imagination, and Vehement Affection, worke greatly opon the Body of the Imaginant: As wee shall shew in due place. [1627]

(5b) Consider besides, how the children perceiuing themselues thus coaxed, and pampered by their parents, keepe themselues, so much as they maye, oute of the dust and the sunne: neither care to apply their mynde to any commendable thing, or to seeke to get more then that liuing which their parentes haue lefte them: not vnlike the crow, which liueth only by the foode whiche other Beastes leaue. And sure there is no doubt of it, but that if they were meanly left by their parentes, they would grow to be wise, and sufficient men. [1581]

(5c) But in order to the unfolding of this doubt, I shall premise four things which will contribute to the better understanding of it. $\langle/ p\rangle\langle p\rangle$ First, There is no doubt that every mans life hath a Period. It is appointed for all men once to dye; this is a warfare from which there is no discharge: what man is he that liveth and shall not see death? [1677]

[6] That the Apostles deliuered many things of this nature to the Churches, some by way of precept, some by way of Councell and advice onely, some to particular Churches, and some to all, some to continue but for a time, and some to continue for euer, we make no doubt. [1628]

(6b) Most diuine Ladie, I beséeche you pardon my offence, I confesse I loued Irus well, because hee was my deare friende, and finding no such misbehauiour in him, since I first knew him, I could not belieue her report, ontill I saw you iustifie the same, and for amends, I offer my selfe to be at your disposition: desiring you to remitte my proffered offence for Irus death: And 
withall, I beséech you make no doubt of my good meaning; For that I haue bent my whole indeuors, with truth to be at your commaund: Neyther harbour any further conceit of violence to be offered you in this place. [1615]

(6c) As if Self-love without pleasure were insufficient for either; for as I my self have known several, who have chosen rather to dye, than to go through tedious courses of Physick; so I make no doubt, but several would have taken the same resolution, rather than have supported life by a perpetual course of eating, which had differ'd in nothing from a course of Physick, if eating and pleasure had not been things inseparable. Now as 'tis pleasure that obliges man to perserve himself, it is the very same that has sometimes the force to prevail upon him to his own destruction. [1698]

(7) During the continuance of this Kingdom, there were many horrible Visions, and strange Signs and Wonders seen both in Heaven, on Earth, and in the Air; foreshewing (no doubt) that God was not well pleased with their actions, which sought to restore that Kingdom of Jerusalem. For, My Kingdom (saith Christ) is not of this World. [1682]

(7b) When the Prelates saw that no obstinacy in the Ambassador, nor Importunity from them, could prevail with the Lord Deputy, to shew what influence they had upon that Treaty, they perswaded the Ambassador to consent to the same Propositions he had formerly (no doubt by the same Advice) rejected; [1680]

(8) Surely you that think sensual pleasure the greatest happiness you are capable of, will suspect that it is not what it appears to your foolish minds, whon God by the Wisest Man doth thus Ironically brand it: he loads you with scorn, while you fondly please your selves with these poor delights, as your only Paradice. God keep me from that as my Portion, which God accounts my reproach. $\langle/ p\rangle\langle p\rangle$ Obj. But may not a Young Man rejoyce? $</ p>\langle p\rangle$ Answ. Yes no doubt, thou oughtest to delight thy self in the Lord, Psal. 37. 4. yea, thou mayst delight moderately and holily in Objects of sence; but that's not the rejoycing here exposed. [1691]

\subsection{Preliminary conclusions: Is there a correlation between collocate patterns and grammaticalization?}

If it can be agreed that an increasing degree of grammaticalization is signalled by the loss of the original meaning, then the loss of the literal sense presumably that of 'unquestionable doubt', i.e. the sense of absolute certainty, can be viewed a sign of such change. Weakening of the certainty value would therefore historically qualify as a change in pragmatic usage. However, that would suggest the original sense is unquestionably known (Traugott (2011) suggests that polysemy of usage may occur early). If 
grammaticalization is to be interpreted as increasing hearer-oriented function (Narrog, 2017) or intersubjectivity (Traugott, 2011), then it follows that the context of patterns must be addressed if we hope to identify pragmatic function accurately. Traugott $(2011,2012,2014)$ suggests that Left and Right Periphery usage may be used as a parameter of pragmatic usage, although the correlation between position and usage must be discussed.

The following section deals with a discussion of the context of patterns and how they can help determine parameters of the usage of ND.

\section{Qualitative analysis: significance of left and right context of ND}

Beeching and Detges (2014) have suggested that there is evidence that the left periphery of the clause is associated with subjective, turn-taking, anaphoric linking to prior discourse, and response-marking, whereas right periphery usage is indicative of intersubjective function, including anticipatory of upcoming discourse, and response-inviting. Traugott's (2014) analysis of modal adverbials surely and no doubt tests the hypothesis that their distribution within the clause can be used as a parameter in assessing changing usage. Left Periphery usage (i.e. left of the core clause), could be indicative of subjective usage, and Right Periphery indicative of intersubjectivity, whereas core clausal usage would signal a standard lexical usage. Although Traugott (2014) showed inconclusive results, i.e. a lack of direct correlation between position and pragmatic value, the following analysis considers $\mathrm{L}$ and $R$ periphery as a potential parameter of change.

\subsection{Left/ right combined distribution patterns of ND}

The collocate results showed two separate patterns of left and right collocates. As the concordance results show, there is some overlap between $\mathrm{L}$ and $\mathrm{R}$ patterns, thus making combined patterns worth exploring. It may be possible and fruitful to establish a larger structure combining left and right nodes, as this might provide more information regarding the distribution of ND in the clause. In other words, can the larger structure provide a wider view and a better understanding of the patterns?

The list below shows the six patterns established from the collocate ranking and their frequency of occurrence. The overall frequency is compared to determine how the patterns interact. If frequencies are similar, there is a likelihood of overlap, which can be verified by carrying out a search.

Let us begin with the left and right collocates that coincide closest: the 
incidence of opening and closing parentheses is extremely close, with a frequency of 1.9 and 1.8 respectively. A search for (ND) combining left and right brackets shows a frequency of 1.6, thus confirming the tendency for no doubt to be used as a clausal or extra-propositional (i.e. discourse) comment in this position, usually on its own. The slightly higher incidence of opening parenthesis shows ND tends to be used at the left periphery of the insert clause.

Consider next the most frequent of all uses, the structure [no doubt but]. The concordance results and a further collocate search for no doubt but show that [There is no doubt but] is the strongest pattern of usage. In this position, ND is used within the core clause as part of the argument structure. The four highest ranking collocates generated of NDB are variants of there, and combined they are by far the most significant.

1. (ND) emerges as the strongest double pattern: (ND as stronger than both (ND) and ND)

2. ND but has a frequency far higher than the others, giving it special salience

3. there is ND emerges as having the second highest frequency

4. there is ND but: A collocate search for there is no doubt shows that the next position is filled significantly by $\boldsymbol{b u t}$. The collocates ranked lower include concerning, left and made. Association measures for each are negative, whereas association measure for $\boldsymbol{b u t}$ is the only positive one, at 3,6 .

5. make ND; 3rd most frequent in general, behind no doubt but and there is no doubt. occurs mostly with I as subject, can occur with but following to the right.

6. ND on't; never occurs with there is. A collocate search for the left position shows this is filled significantly by make, the only ranking collocate with a non-negative AM score of 2,4. However, the concordance results show very few instances of usage, i.e. 12 tokens, with a low frequency of 0.01 . Instead, $N D$ on't seems to be used as an isolated structure, embedded using punctuation signs to the left and right. A further search for possible alternations for on't shows that $N D$ on is very rare and does not coincide with the same usage as ND on't. Indeed, no doubt on is followed by no doubt on my side; no doubt on my mind, etc. However, ND of is twice as frequent as no doubt on't, suggesting of complementation has survived to the detriment of historical on complementation. 


\subsection{Summary: correlation between pragmatic value of collocate patterns and distribution}

How do the positions of ND correlate with clausal distribution? In other words, what is the significance of $\mathrm{L}$ and $\mathrm{R}$ periphery distribution, in comparison with core clausal structure? Table 6 gives an overview of the correlation of -1 and +1 patterns with regards to the position within the clause. The patterns TIND, MND are core clausal features; the patterns YND and NDB tend to be LP positions; NDwould/will has medial position, while parenthetical use varies between $\mathrm{L}, \mathrm{R}$ and medial positions, and finally NDont tends to be in $\mathrm{R}$ position, but can be medial.

Table 6: Overview of -1 and +1 patterns and correlation with clausal distribution.

\begin{tabular}{|c|c|c|c|c|c|}
\hline $\begin{array}{l}-1 \\
\text { pattern }\end{array}$ & Position & $\begin{array}{l}\text { Pragmatic modal } \\
\text { value }\end{array}$ & +1 pattern & Position & $\begin{array}{l}\text { Pragmatic } \\
\text { modal value }\end{array}$ \\
\hline TIND & Core clause & $\begin{array}{l}\text { Emphatic } \\
\text { focalized, } \\
\text { argumentative, } \\
\text { certainty }\end{array}$ & NDB & LP & Concessive \\
\hline MND & Core clause & $\begin{array}{l}\text { Emphatic } \\
\text { evidential, } \\
\text { argumentative, } \\
\text { certainty }\end{array}$ & NDwould/will & Medial & $\begin{array}{l}\text { Irrealis, } \\
\text { hypothetical } \\
\text { certainty }\end{array}$ \\
\hline (ND & $\mathrm{LP} /$ medial & $\begin{array}{l}\text { Insert function, } \\
\text { weaker certainty }\end{array}$ & $\mathrm{ND)}$ & $\begin{array}{l}\text { LP/ } \\
\text { Medial/RP }\end{array}$ & $\begin{array}{l}\text { Insert, lower } \\
\text { certainty }\end{array}$ \\
\hline YND & LP & $\begin{array}{l}\text { Argumentative, } \\
\text { concessive }\end{array}$ & NDont & $\mathrm{RP} /$ medial & $\begin{array}{l}\text { Emphatic, } \\
\text { anaphoric }\end{array}$ \\
\hline
\end{tabular}

Let us first address the issue of proposing pragmatic values for a historical corpus. It must be said at this stage that inferences as the meaning of expressions in a diachronic corpus pose issues that do not arise in a contemporary corpus. How to identify the semantics and pragmatic implications of these structures reliably, without imposing current-day English patterns on the data remains an open question and cannot be resolved within the scope of this paper (see Bromhead 2009, Eckhart et al. 2003, Nevalainen 2006 on specific features of Early Modern English or EModE). Notwithstanding this caveat, Table 6 does show that the distribution of ND in the EHBO tends to be core clausal or Left Periphery positions, rather than Right Periphery. Nevertheless, a more accurate view of the data may be achieved by looking at combined patterns of usage of $\mathrm{ND}$, as seen in Table 7. The interaction of $\mathrm{L}$ and $\mathrm{R}$ collocates is observable in Table 7 column 3, providing a more global view of the patterns. Column 4 gives comparative frequency of double patterns compared with single 
patterns, showing quantitatively what proportion of collocates interact with each other. Each individual pattern in column 1 has between 1 and 5 L\&R patterns in column 3.

Table 7: Compared L and R patterns of ND.

\begin{tabular}{|c|c|c|c|}
\hline $\mathrm{R}$ or $\mathrm{L}$ pattern & $\begin{array}{l}\text { Frequency per } \\
\text { mil }\end{array}$ & L \& R patterns & Frequency per mil \\
\hline ND but & 5.9 & $\begin{array}{l}\text { there is ND but } \\
\text { there was ND but } \\
\text { make ND but } \\
\text { punctuation sign + ND }\end{array}$ & $\begin{array}{r}1.5 \\
0,1 \\
1.00 \\
\text { negative }\end{array}$ \\
\hline ND) & 1.8 & (ND) & 1.6 \\
\hline ND on't & 0.1 & $\begin{array}{l}\text { make ND on't } \\
\text { ND of } \\
\text { ND on }\end{array}$ & $\begin{array}{r}0,01 \\
2 \\
0.05\end{array}$ \\
\hline ND would & 0.2 & No significant L collocates & Negative \\
\hline There is ND & 3.3 & $\begin{array}{l}\text { there is ND that } \\
\text { there is ND but } \\
\text { there is ND of } \\
\text { there is ND on't }\end{array}$ & $\begin{array}{r}0.1 \\
1.5 \\
0.2 \\
0\end{array}$ \\
\hline (ND & 1.9 & $\begin{array}{l}\text { (ND) } \\
\text { (ND will }\end{array}$ & $\begin{array}{r}1.6 \\
0.01\end{array}$ \\
\hline Yes ND & 0.1 & R Punctuation & Negative \\
\hline Make ND & 2.9 & $\begin{array}{l}\text { I make ND } \\
\text { need/ neede make ND } \\
\text { make ND but } \\
\text { make ND on't }\end{array}$ & $\begin{array}{l}1.66 \\
0.01 \\
0.95 \\
0.01\end{array}$ \\
\hline
\end{tabular}

What can the combinations of patterns and their compared frequencies tell us about ND? The data bring to the foreground some of the alternations that may be relevant historically in terms of the frequency for the period (1500-1800). In descending order of frequency in the corpus, four patterns emerge:

a) NDB: often coincides with TIND and MND

b) TIND: has 3 variations of complementation. BUT is by far the most frequent over THAT and OF. Traugott (2011: 69) shows the historical origins of the subordinative BUT, which was gradually replaced as a complementizer by THAT.

c) MND: I + MND is by far the most frequent within the class. The use of the personal pronoun I as subject shows the usage is firm stance- 
taking, and signals high certainty of the speaker.

d) ND: the only significant correlation between L\&R collocates shows the relevance of parenthetical structure. The frequency of opening bracket and closing bracket are quite comparable, indicating that ND tends to either introduce or conclude the parenthetical comment.

The combined patterns allow for a better understanding of the possible alternations that can occur for a given pattern. However, as far as the methodology of the diachronic study is concerned, it seems preferable to avoid reducing the datasets. Given that BUT complementation is by far the most frequent, it will be kept as a separate pattern from the existential formula TIND and the verbal structure MND. In the case of parenthetical use, the opening parenthesis will be taken as a guideline as ND appears more frequently in initial position within the parenthesis. I also choose to keep NDont despite its relative infrequency compared to OF, because of its high AM score, which indicates a strong correlation despite its low frequency.1 - NDB; 2 - TIND; 3 - MND; 4 - (ND; 5 - Ndont.

\subsection{Discussion of patterns: clausal distribution and pragmatic interpretation}

The preceding collocate analysis shows that ND is used essentially in five significant patterns. As can be observed, these patterns include both left and right distribution, although most patterns include exclusively left, or exclusively right distribution, the only exception being the opening and closing brackets. It remains to be determined how to measure the interaction of these patterns rather than observing them independently.

Let us first consider the semantic and pragmatic implications of the patterns in terms of speech act orientation, pragmaticalization, i.e. acquisition of so-called "procedural" meaning. As suggested above, an early sign of change is a loss of original lexical meaning, which occurs when ND no longer is concerned with absolute certainty but rather degrees of certainty or uncertainty. For Narrog (2017), grammaticalization is signalled by increasing speech act orientation. How do these five patterns correlate with signs of increasing speech act orientation and lessening degrees of certainty?

Both MND and TIND seem to be on the absolute end of the scale, and show no signs of speaker-orientation, indicating they are early non grammaticalized uses of ND.

Beyond the absolute original "contentful" sense of absolute certainty, ND takes on a procedural meaning where ND can be either an emphasizer or a mitigator, possibly evidential in that its use indicates distance between the 
reported speech as the speech act itself. This is the speaker taking a stance for rhetorical purposes, see the historical narratives in (9) and (10). Consider the following examples from the concordance to test these hypotheses. The use of ND is emphatic and argumentative in (9) and concessive/ epistemic / evidential in (10). For Traugott (2011: 69) ND “is subjective, signals personal inference and assessment, hence use in concessives."

(9) As concerning the temperature of beere there is no doubt but that it is hot, Galen saith) be nothing else but a water, which in processe of time purchaseth a hot substance to it selfe in the stocke and woodie parts of the vine... [1616]

(10) Thirdly, although there be no mention made of the Disciples drinking: yet no doubt they did drinke, as well as eate before they rose. [1630]

When $N D$ is used extra propositionally, it is a modal judgment signalling conjecture regarding propositional content as in (11), (12) and (13). From the concordance, it appears many of the uses of this conjectural no doubt are narrative hedging devices used in storytelling (History, Bible) but also reasoning and rhetoric in (13). It has a weaker modal value as it does not express high certainty but functions more as an evidential (sufficient evidence for inference to be made).

(11) Beside, the originall Greeke hath not oenly beene kept by the Greeke Church, but also by the Latine Church, which Latine Church, no doubt, had as great, or greater care to preserue the Originall from corruption, then the Latine Translation. [1630]

(12) You will finde them (no doubt) when you know them stout iudicious persons and of a deepe reach, to determine so great a doubt as this which wee haue in hand. [1631]

(13) But difputants do not always convey information. There is (no doubt) a great majority of members who will vote according to their difpaffionate judgment; and fuch men will naturally wifh to form opinions on plain reafon plainly delivered. To them therefore this paper is addreffed [1785]

At this juncture, it is important to remember that this picture is an overall view of the usage of $N D$ in EHBO. The concordance examples here are Early Modern English to $18^{\text {th }}$ century, however, the historical corpus has a depth of several centuries (1473 to 1820). The question is whether patterns of usage may differ from one period to the next, and if from the data, a larger pattern of directionality of change can be determined from this study. Additional confounding factors that may affect the data need to be addressed carefully, such as in particular the impact of text type and inconsistencies in frequency for varying periods.

The following section deals with the historical approach and its pitfalls. Firstly, I consider the frequency statistics and examine how to determine 
timeline partitioning. Only then can patterns of usage be compared for each period.

\section{Timeline partitioning and method for identifying dia- chronic behaviour}

\subsection{Compared frequency over time periods}

I take a somewhat non-traditional approach to diachronic study. Instead of relying on the standard historical English periods as time slices, as in Davidse, De Wolf \& Van Iinden (2011), I will follow the methodology outlined in Hilpert \& Gries (2016), which argued that ad-hoc timeline periodization cannot provide an adequate method for identifying significant change insofar as it relies on arbitrary slices of time. The methodological question raised is how to partition the corpus to ensure the most reliable and significant data. The first issue at hand is to consider the makeup of the corpus itself in terms of data per period.

Table 8: Subcorpora statistics for EHBO provided by Sketch Engine.

\begin{tabular}{|r|r|r|r|}
\hline subcorpus & \multicolumn{1}{|c|}{ tokens } & \multicolumn{1}{|c|}{ Words } & \multicolumn{1}{c|}{$\%$} \\
\hline $1473-1499$ & 6797076 & 5688975 & 0,68 \\
$1500-1599$ & 115081926 & 96320574 & 11,65 \\
$1600-1699$ & 667854918 & 559977172 & 67,64 \\
$1700-1799$ & 190169554 & 159166963 & 19,26 \\
$1800-1820$ & 7338773 & 6142361 & 0,74 \\
ECCO & 82127359 & 68738460 & 8,31 \\
EEBO phase 1 & 792281394 & 663118891 & 80,25 \\
EVANS & 112833494 & 94438695 & 11,42 \\
No doubt conc & 553464538 & 448169872 & 54,23 \\
\hline
\end{tabular}

The EHBO corpus data is analysed into subcorpora showing the composition of the corpus for each century from 1473 to 1820, as shown in Table 8. Column 2 provides the total number of tokens and words to the total number of words for each century, while Column 3 gives the corresponding proportion each century represents for the entire corpus. Line 1 represents the overall EHBO data for the period ranging from 1473-1499, Line 3 represents the overall EHBO data for the period 1500-1599, and so on. Lines 6, 7 and 8 represent the total number of tokens and words in the EEBO Phase 1, the ECCO and EVANS projects, while line 9 quantifies the concordance results for ND corpus: this subcorpus represents $54 \%$ of the overall EHBO corpus.

What Table 8 clearly shows is the extreme data variation from one century to the next. The discrepancies of usage per century are considerable: 
only the period ranging from 1500-1800 provides non-negligible data (i.e. over 10\%). The century 1600-1699 far outweighs all others by at least 3 times, representing over $67 \%$ of the data in the $\mathrm{EHBO}$.

To verify this picture of the data, let us now consider the frequency of usage of $N D$ across the entire period covered by the EHBO. Figure 1 shows the raw frequency and relative frequency of ND over the period 1500-1820 per decade. Y axis shows the raw frequency, ranging from 1 to around 3500, $x$ axis represents the 30 decades ranging from $1500-1799.0$ represents 1500 1509,1 represents $1520-1529$, as there is no data for $1510-1519$.

Figure 1: Raw and relative frequency of ND per decade 1500-1799.

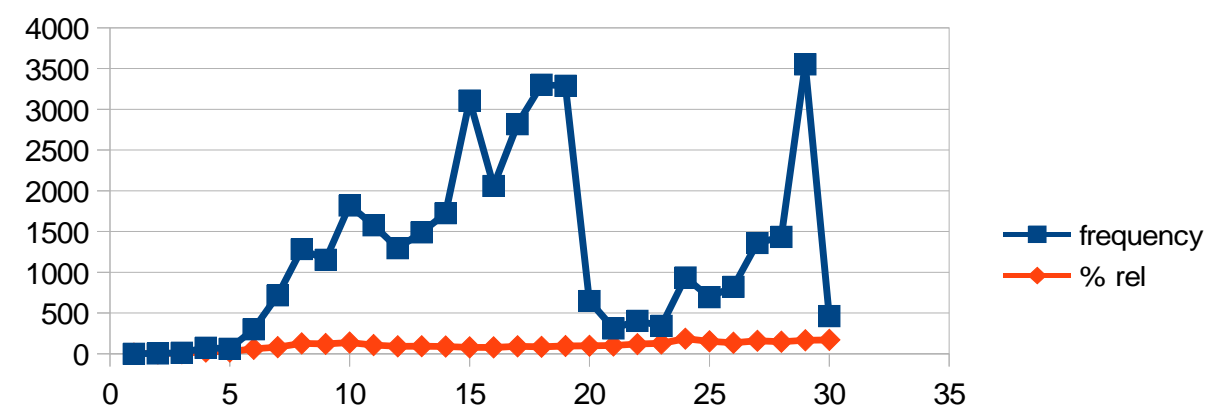

As expected, based on the subcorpora statistics in Table 7, the line representing raw frequencies shows very considerable highs and lows from one period to the next, specifically in the range of 1700 . There is a considerable drop in frequency at 1700 mark, indicating that were very few tokens of $N D$ for this time period. This poses the question of whether this drop is significant, or if it can be attributed to a lack of data for that period. To investigate the cause of this drop, let us now consider the relative text type frequency per decade. The graph in Fig 2 shows a far more balanced picture than the raw frequencies for each decade in Figure 3. Relative text type frequency considers the raw frequency of the target expression and indexes it to the data available for that text type, in this case decade partitioning. It can be interpreted as 'how much more/less often is the result of the query in this text type in comparison to the whole corpus'. On closer inspection in Figure 2, the relative frequency (RF) shows a far less significant drop in frequency from 1660 to 1700 . This suggests that the usage of ND for that period is less frequent not because the expression became disused, but simply because the data range is smaller. The availability of data is an issue for historical corpora as it affects the timeline considerably. 
Figure 2: RF of ND from 1500 to 1789 per decade.

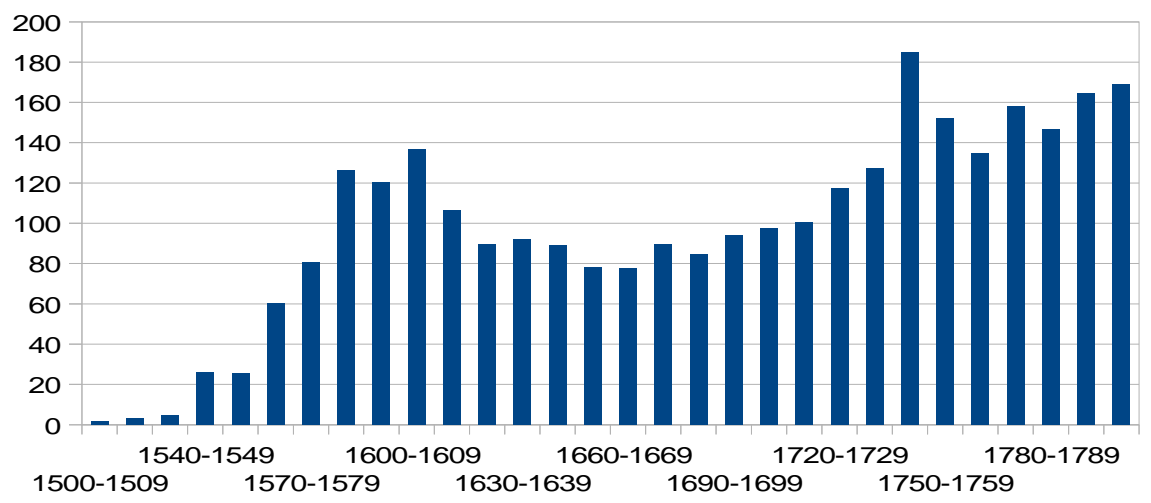

The second observation based on Figure 2 confirms the general view provided by subcorpus statistics. Figure 2 shows clearly that data only become reliable from 1580, as was expected from the data in Table 8 . The period preceding 1580 has far fewer uses of ND not only absolutely but also relatively, and therefore is too sparse to generate any representative patterns. The period covered hereafter will be 1600 to 1800 , so it encompasses the later part of early modern English 1500-1700, and 18 century English, i.e. 1700-1800. The next section aims to discuss the partitioning of the timeline to consider how it affects potential patterns of usage.

\subsection{Timeline partitioning}

As discussed in Hilpert \& Gries (2016), timeline partitioning is a crucial factor affecting the results of a historical corpus analysis. The best course of action following Hilpert \& Gries (2016) is to follow the natural time slices of the data. In this case, the use of ND over time shows that there are three distinctive time slices as follows. Note that I use the term period loosely here in the sense of time slice, rather than in the traditional sense of set historical periods.

1) PERIOD 1: 1579-1669, slight rise, slight fall to lowest dip. (Early Modern English)

2) PERIOD 2: 1670-1759: steady rise from lowest dip (Early Modern -> $18^{\text {th }}$ century English)

3) PERIOD 3: 1760-1799: rise to the highest point, fall to reach a steady level (18 th $^{\text {th }}$ century English) 
This partitioning into three periods provides a basis for: a) analysing the incidence of time on patterns; and b) analysing the incidence of text type on RF.

\subsection{Correspondence between ND patterns and time slices}

This subsection investigates the compared frequency of each of the six patterns identified in 1.6 for each of the three time slices identified in 2.2: 1NDB; 2 TINDB; 3. MND; 4 - TIND; 5- (ND); 5 -(ND, 6. NDont.

Table 9 below summarizes the data collected from the EHBO for each consecutive period from 1580-1799. The tokens of each pattern are found in the first column of each period, followed by the proportion of usage of that pattern relative to the total ND frequency for that period. The resulting graph shown in Figure 3 represents the proportion of usage of each pattern relative to the overall ND usage for the period. Thus, we get a comparative view of the usage of the patterns of ND for each of the three periods under study.

Table 9: Frequency per pattern for each time slice and proportion of total ND usage for that period.

\begin{tabular}{|c|c|c|c|c|c|c|c|}
\hline \multirow[t]{2}{*}{ Pattern } & $1420-1820$ & $1580-1669$ & $1580-1669$ & $1670-1759$ & $1670-1759$ & $1760-1799$ & $1760-1799$ \\
\hline & Freq & TOKENS & $\%$ of ND & TOKENS & $\%$ of ND & TOKENS & $\%$ of ND \\
\hline NDB & 5.9 & 2285 & 18.09 & 2269 & 17.81 & 972 & 13.56 \\
\hline TINDB & 1.5 & 582 & 4.6 & 629 & 4.93 & 225 & 3.13 \\
\hline MND & 2.9 & 1217 & 9.63 & 1003 & 7.87 & 592 & 8.26 \\
\hline ND) & 1.6 & 1225 & 9.7 & 289 & 2.6 & 20 & 0.27 \\
\hline (ND & 1.9 & 1369 & 10.84 & 407 & 3.19 & 37 & 0.51 \\
\hline TIND & 3.3 & 1487 & 11.77 & 1172 & 9.2 & 449 & 6.26 \\
\hline NDont & 0.15 & 18 & 0.14 & 126 & 0.98 & 4 & 0.05 \\
\hline $\begin{array}{l}\text { ND } \\
\text { general }\end{array}$ & & 12627 & & 12739 & & 7166 & \\
\hline
\end{tabular}


Figure 3: \% of total ND usage per pattern per period

$\%$ of total ND per period per pattern
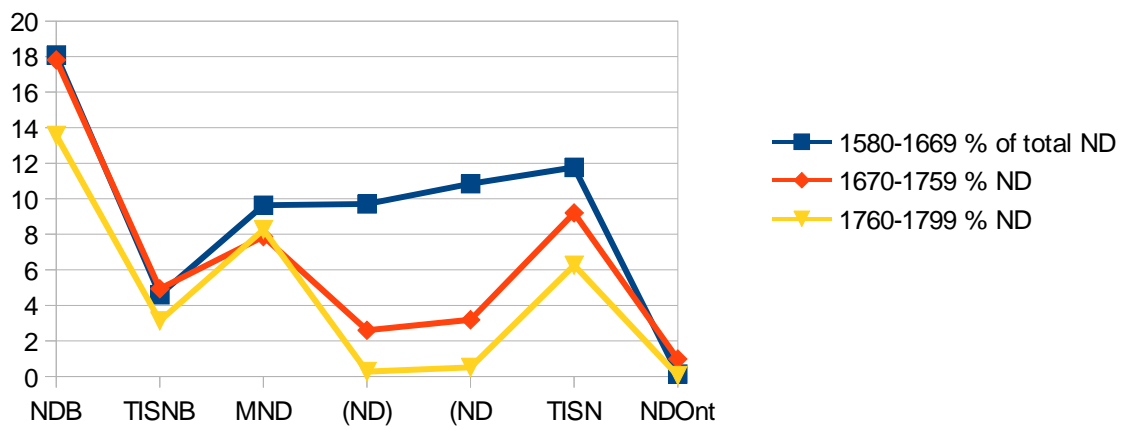

Figure 3 shows three lines representing the compared proportion of each pattern relative to the usage of ND for each period. The three lines show a somewhat consistent proportion of NDB for each period, and the general proportions remain similar for $1670-1759$ and $1760-1799$. It is the earliest period 1580-1669 that shows the most divergence, i.e. the usage of parenthetical ND. However, these data give us an absolute view of the situation, without accounting for variation of ND usage from one period to the next. This means the general observations may be true in the absolute but do not give information on the proportion of usage of ND. The diverging sets of data are a confounding factor, in so far as the relative usage of ND within each time period must be considered, i.e. the frequency of ND in relation to the total word count of each period.

The following section compares the RF for each pattern in the three different periods, in the aim of identifying patterns of usage. Once patterns are identified, explanations and considerations of confounding factors such as text type will be addressed.

\subsection{RF of patterns per period}

The following section compares the RF of the five patterns for each of the three consecutive time periods. The patterns are abbreviated to NDB, NDon't, (ND, MND, TIND. The three graphs in Figures 4 to 6 below show the comparative RF of all five patterns per decade with the period chosen in comparison with the relative frequency of ND in general.

The comparison between the RF of each individual pattern with the RF of ND tells us how closely the pattern follows the general pattern. In the case of a disparity between RF of ND and RF of a single pattern, the divergence may be the sign of an outlier, which will require some qualitative 
investigation.

Figures 4-6: RF of ND patterns per decade for Period 1 (1580-1669), Period 2 (1670-1759) and Period 3 (1760-1799).

\section{RF for ND patterns period 1}

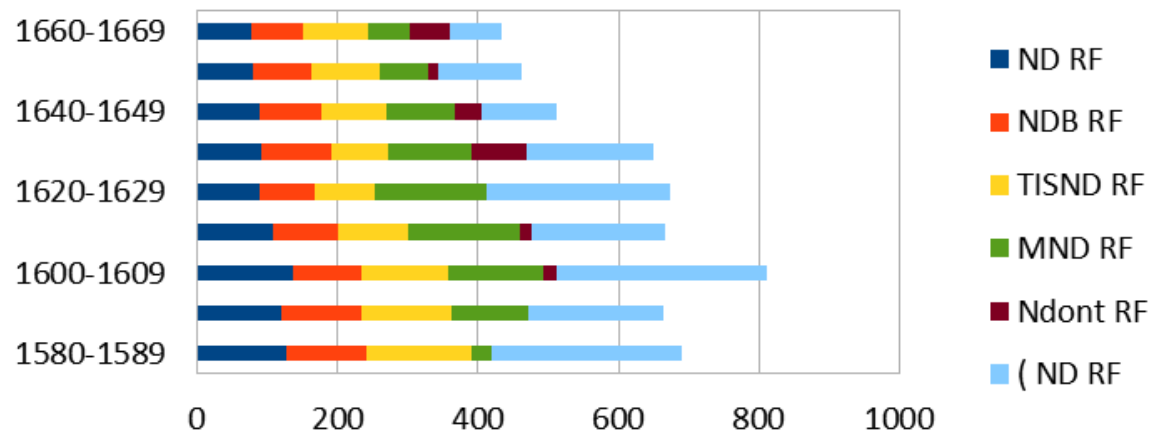

RF of ND patterns for period 2

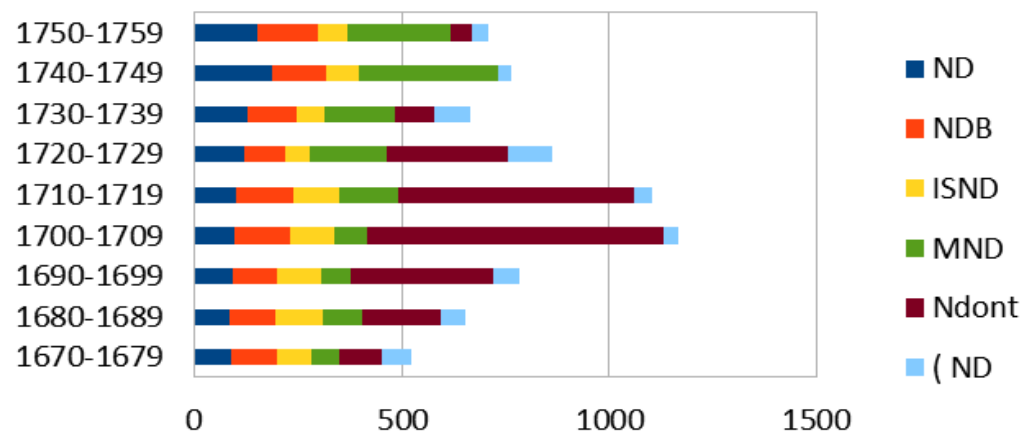

RF of ND for period 3

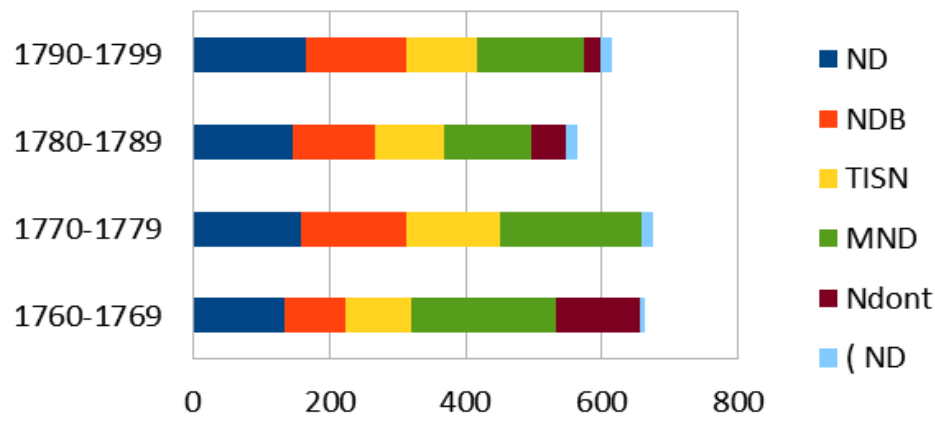


The observations from the data reveal some consistencies within each period, but also some marked disparities, especially regarding three patterns, namely (ND, NDont, and MND.

1) There is a higher RF of insert use of parenthetical (ND indicated by use of open brackets in Period 1 (1580-1669) than any other period. Period 1 also exhibits the most constant relative frequency of the overall use of ND.

2) There is a higher RF of use of cataphoric or anaphoric, focalising use of NDon't in Period 2 (1670-1759) than any other period. This period also coincides with a fall in relative frequency of ND.

3) NBD and TIND are consistent with the overall use of ND. They seem to be most closely indexed to the general ND pattern for all 3 periods.

4) MND (arguably the most lexical pattern) displays a higher degree of variation from one decade to the next within each period, also tending to diverge from the RF of ND.

\section{Discussion of patterns: the diachronic behaviour of ND}

\subsection{Confounding factors and questions}

A major confounding factor in the study of historical discourse markers is the absence of an oral corpus (speech or conversation), and the reliance on exclusively textual resources. Given that pragmatic markers mediate messages between speakers and hearers, or writers and readers, interactivity is key (Culpeper \& Kytö 2010). However, Jucker (2002) shows that plays, letters, trial records have higher frequencies of discourse markers. Culpeper \& Kytö (2010: 15) and Rissanen (1999: 188) point out that EModE (period 1) text type combines a wide variety of styles and registers: sermons, records of debates, comedies, novels, histories, plays. Culpeper \& Kytö (2010: 17) propose three categories to classify speech-related genres: Speech-like, e.g. Personal Correspondence; Speech-based e.g. Trial proceedings; Speechpurposed, e.g. Plays.

Given this caveat, and previous methodology, it is feasible to consider the following questions for discussion of the relative frequency of ND patterns in the EHBO: are the observations consistent with previous diachronic findings (Traugott 2011, 2012, 2014) and Simon-Vandenberger (2007)?

\subsection{Are the observations consistent with other diachronic findings?}

Yes, this data set does appear to be consistent with previous findings to some extent. It verifies some of the conclusions reached by Simon- 
Vandenberger (2007), namely (1) the existential use of ND (there is no doubt) pre-existed the adverb, (2) the semantic and pragmatic versatility has increased, and (3) no doubt has become a discourse marker. The findings here appear to validate both 1) and 2). However, there may not be sufficient evidence of ND as a modal marker, possibly due to the timeline of the corpus. For instance, Traugott (2011) showed evidence of grammaticalization post 1800, although Traugott (2011) dates the epistemic use of ND to 1710, whereas Simon-Vandenberger \& Aijmer (2007) rely on ICE corpus data, a contemporary synchronic corpus. This suggests that EModE period may coincide with the early use of ND before its acquisition of discourse marker status, which might therefore be dated later (1800-1900). Another plausible cause is that the data set might not be sufficiently adapted to pragmatic analysis, given the text type ratio. For an overview, see Olga Fischer (2008) on the development of epistemic modals.

\subsection{What variations and disparities say: ND outliers}

What is the significance of the diachronic variations from one period to the next? Specifically, why is there a time-specific use of NDont in period 2 (1670-1759)? What alternations replaced it, if any? Also, why the increase in MND in period 3 (1760-1799), which seems counterintuitive as one would expect less clausal use and more peripheral usage? Finally, what could be the cause of the declining parenthetical structure? Could this be interpreted as a precursor of grammaticalization? Narrog (2017: 109) notes that some markers enter the level of speech act orientation directly, rather than through event-oriented modality. He states the case of discourse and epistemic markers that develop out of parenthetical constructions such as I'm sure.

The purpose here is to consider the striking disparities in usage of NDont and (ND in correlation with the period. Is the disparity significant, i.e. can it be reproduced in another corpus? A text-type analysis might help clarify the parameters explaining relative increases in some patterns in certain decades.

Firstly, let us consider the concordance results for the periods showing the highest diverging data sets, observed in the preceding section. Namely (ND for period 1 showing a relative increase in comparison with ND general and individual patterns, and NDon't for period 2 also showing a remarkable disparity between overall RF and individual RF.

Let's start with the first pattern of interest (ND for the decade 1600-1609 illustrated in (14) and (15). The usage in context shows that the use of (ND has a reporting value in (14) with evidential value as observed by the use of if it be true, and references to the reliability of the source. (15) shows a reference to belief in god's will (possibly humorous) with a modal or 
evidential reporting value (that can either pragmatically validate or question the source). Given the nature of the work the excerpt is taken from (a comedy), it is highly likely the effect is humorous or farcical.

(14) $\mathcal{E}$ rating the cowardise of his enemie, with great joy and gratulation, rode back as conqueror into the campe. Some Annales and Chronicles do record and adde to this combat of horsemen, astraung and wonderfull thing (no doubt) if it bee true, as by the common opinion it is reputed no lesse: namely, that when Taurea fled back into the cittie, Claudius followed hard after him in chase... [1600]

(15) Thou shalt not want, as I am a gentleman: Woman, be patient, God (no do$\underline{u b t)}$ wil send Thy husband safe againe, but he must go, His countries quarrel sayes, it shall be so. $\langle p\rangle$ Hodge $\langle/ p\rangle\langle p\rangle$ Thart a gull by my stirrop, if thou dost not goe, [1600] PLAY (COMEDY)

The second pattern of interest is no doubt on't for for period 2, specifically 1700-1709 in (16), (17), (18), (19). It appears from the concordance results that many are extracts from PLAYS (COMEDIES), and SERMONS; either direct quotes as in (17), (18), (19), (20) or indirect quotes as in (16).

(16) Man enters into Articles very readily before Marriage, and fo he may, for he performs no more of them afterwards than he thinks fit. A Wife muft never difpute with her Husband, his Reafons are now no doubt on't better than hers, whatever they were before; he is fure to perfwade her out of her Agreement, and bring her, it muft be fuppos'd,

(17) yet for their comfort he tells them that this in conjunction with the two former will be very eafy and pleafant, and will or fhould be fufficient to pleafe their Husbands; P. 44. Ay good Sir! no doubt on't, unlefs they are Men that fall infinitely fhort of the leaft Jhare of Reafon, Confcience and Humanity [...].

(18) Drum I heard indeed, and saw it, a Boy was beating it; Hunting Squirrils by Moon-Light. $</ \mathrm{p}><\mathrm{p}>$ Curi. $</ \mathrm{p}><\mathrm{p}>$ Nothing else, upon my Word, Sir. $</ \mathrm{p}><\mathrm{p}>$ Alph. $</ \mathrm{p}><\mathrm{p}>$ That Rogue, the very Boy, no doubt on't, that haunted me all last Night. I wish I had him, he has plagued my heart out. But come, let's go in, and let me get on my Cloaths [...].

(19) A Man too. Only to bring me into Difgrace with a certain Woman of Quality - $</ \mathrm{p}><\mathrm{p}>$ Scan. $</ \mathrm{p}><\mathrm{p}>$ Whom we all know. $</ \mathrm{p}><\mathrm{p}>$ Tatt. $</ \mathrm{p}><\mathrm{p}>$ No matter for that - Yes, yes, every Body knows - No doubt on't, every Body knows my Secrets - But I Joon Jatisfy'd the Lady of my Innocence; for I told her-Madam, fays I, there are fome Perfons who make it their Bufine ss to tell Stories [...].

(20) Tatt. $</ \mathrm{p}><\mathrm{p}>$ Brag! O Heav'ns! Why, did I name any body? $</ \mathrm{p}><\mathrm{p}>$ Ang. $</ \mathrm{p}><\mathrm{p}>$ No; I Juppofe that is not in your Power; but you wou'd if you cou'd, no doubt on't. $</ \mathrm{p}><\mathrm{p}>$ Tatt. $</ \mathrm{p}><\mathrm{p}>$ Not in my Power, 
Madam! What, does your Ladyfhip mean, that I have no Woman's Reputation in my Power? $</ \mathrm{p}><\mathrm{p}>$ Scan. $</ \mathrm{p}><\mathrm{p}>$ Ouns, why you won't own [...].

\section{Summary and concluding remarks}

This study carried out a collocate analysis of ND in the EHBO with a purpose to determining the diachronic behaviour of the modal expression $\mathrm{ND}$ and comparing the results with conclusions of previous diachronic pragmatic studies of modal markers. The first step was to determine significant collocate patterns using Sketch Engine, considering left and right collocate candidates. Five significant patterns were identified, based on LogDice association measure, in decreasing order of frequency: 1 - NDB (no doubt but); 2 - TIND (there is no doubt); 3 - MND (make no doubt); 4 - (ND (parenthetical use); 5 - Ndont (no doubt on't).

The second part of the study was to carry out a historical partitioning of the EHBO corpus following Hilpert \& Gries (2015). This partitioning produced three distinct time slices covering Early Modern English and Late Modern English (1580-1669, 1670-1759, 1760-1799). I set out to answer the following three questions:

a) If and how do the patterns of usage of ND in the EHBO evolve over time? How can we accurately determine patterns and their interpretation?

b) What features signal increasing grammaticalization and what can clausal distribution tell us (Traugott 2011, 2012, 2014)?

c) How do the data compare with Simon-Vandenberger \& Aijmer's (2007) corpus-based study using ICE (International Corpus of English) and Traugott's findings on ND $(2011,2012,2014)$ ?

Firstly, the data provided showed that relative usage of ND is remarkably consistent over all three periods. This means that, if change occurs, it is gradual and non-linear. The most consistent are the lexical uses of MND and TIND, which are viewed as non-grammaticalized uses of the expression. These uses remain consistent over all three periods, showing no signs of decrease, as might have been expected. However, Davidse et al. (2011) argue in their history of ND that the expression defies the usual orientation of grammaticalization by emerging with modal meaning and developing lexical senses later. According to Davidse et al. (2011) no doubt was used early on as a discourse marker intended for the addressee with the sense "have no fear", and then quickly evolved to the discourse marker sense "we are in agreement". For Davidse et al. (2011), the decrease in parenthetical use of ND signals an evolution into a less discursive and more formal use of ND based on the existential TIND. 
In the EHBO data, NDont and parenthetical (ND were shown to be the least consistent overall. NDont was found to be significant only for period 2, (ND peaking in period 1. The findings do not show evidence of definitive linear shift in patterns of ND. Several factors could explain this: 1) evidence of shift, i.e. evidence of grammaticalization, may occur later than the corpus timeline (post 1800) or 2) the corpus data may not be sufficiently reliable to carry out a statistical analysis or 3) the history of ND may not follow usual pathways as per Davidse et al. (2011). To test the validity and significance of the results, a comparison with another historical corpus of Early Modern English such as the Helsinki Middle English corpus, or the Penn Historical Corpus, would enable us to consider different parameters between corpora which might account for varying results. For instance, can the spike in frequency for (ND and NDont be replicated in another corpus for the same period in a similar genre (plays, sermons)? If not, it can be assumed that the results are too corpus specific. As a concluding remark, sociolinguistic issues link increasing epistemicity and evidentiality with epistemological change (Bromhead 2009, Wierzbicka 2006). Sociolinguistics and sociocultural evidence from Wierzbicka (2006) and Bromhead (2009) show a shift from an era of certainty to a post Enlightenment era of doubt. Wierzbicka (2006: 296) suggests that the rise of epistemic modals in EModE reflects a rise in epistemological concerns for the same period, triggered by the ideas developed in Locke's Essay on Human Understanding (1690) and the consequent growth of a new class. The advent of probably and I think are seen to epitomize the drastic changes of modern Anglo discourse. However, such generalizations are risky and tracing the histories of modal expressions is required. If it is true that ND does not follow established patterns of grammaticalization, then we still need to establish what diachronic pattern it follows.

\section{Sources of data}

The Oxford English Dictionary, Subscription version 3. Online. https://www.oed. com/. Last accessed on 5/08/2019.

Early English Books Online (EEBO), Oxford Text Archive OTA, via Sketch Engine. Last accessed on 5/08/2019.

English Historical Book Collection, comprising EEBO, ECCO and EVANS, accessed via Sketch Engine. Last accessed on 5/08/2019

Kilgarriff, Adam et al. The Sketch Engine. http://www.sketchengine.eu. Last accessed on 5/08/2019.

EEBO, ECCO and EVANS corpora references last accessed on 5/09/2019 via Sketch Engine using Oxford Text Archive 
(1) A Briefe and Plaine Declaration, concerning the desires of all those faithfull Ministers, that haue and do seeke for the Discipline and reformation of the Church of Englande. London, 1584. http://tei.it.ox.ac.uk/tcp/Texts-HTML/free/A00/ A00283. html

(2) Bacon, Francis. Sylua syluarum: or A naturall historie In ten centuries. London, 1627. http:/ / tei.it.ox.ac.uk/tcp/Texts-EPUB/free/A01/A01552.html

(3) Astell, Mary. Some Reflections upon Marriage, Occasion'd by the Duke \& Dutchess of Mazarine's Case; Which is also consider'd. London, 1700. http://tei.it. ox.ac.uk/tcp/Texts-HTML/free/A26/A26097.html

(4) Eubieus, of Ceasarea. The auncient ecclesiasticall histories of the first six hundred yeares after Christ, wrytten in the Greeke tongue by three learned historiographers, translated from Greek. London, 1577 http://tei.it.ox.ac.uk/tcp/Texts-EPUB /free/A00/A00440.html

(5) Bacon, Francis. Sylua syluarum: or A naturall historie In ten centuries. London, 1627. http:/ / tei.it.ox.ac.uk/tcp/Texts-EPUB/free/A01/A01552.html

(5b) Guazzo Steeuen. The Civile Conuersation Translation by Pettie, George. London, 1581. http://tei.it.ox.ac.uk/tcp/Texts-EPUB/free/A02/A02291.html

(5c) Allestree, Richard. A Discourse Concerning the period of Humane Life: Whether Mutable or Immutable. London, 1677. http://tei.it.ox.ac.uk/tcp/Texts-EPUB/ free/A23/A23713.html

(6) Field, Richard. Of the Church, Five Bookes. Oxford, 1628. http:/ / tei.it.ox.ac.uk/tcp/Texts-EPUB/free/A00/A00728.html

(6b) Ford, Emanuel. The First Part of Parismvs, The Renovvemed Prince of Bohemia. His most famous, delectable, and pleasant Historie. London, 1615. http://tei.it.ox. ac.uk/tcp/Texts-EPUB/free/A01/A01066.html

(6c) Collier, Jeremy. The Usefulness of the Stage, To the Happiness of Mankind. To Government, and To Religion. London, 1698. http://tei.it.ox.ac.uk/tcp/TextsEPUB/free/A35/A35682.html

(7) Bunting, Henry. Itinerarivm Tottiys Sacrae Scripturae: Or, The Travels of The Holy Patriarchs, Prophets, Judges, Kings, English Translation by R. B. London. London, 1682. http://tei.it.ox.ac.uk/tcp/Texts-EPUB/free/A30/A30018.html

(7b) Borlase, Edmund. The History Of the Execrable Irish Rebellion Trac'd from many preceding Acts, To The Grand Eruption The 23. of October, 1641. And thence pursued to the Act of Settlement. London, 1680. http://tei.it.ox.ac.uk/ tcp/Texts-EPUB/free/A28/A28828.html

(8) Williams, Daniel. The Vanity of Childhood \& Youth. London. 1691 http://tei.it.ox. ac.uk/tcp/Texts-EPUB/free/A66/A66355.html

(9) Stevens, Charles \& Liebavut John. Maison Rustique, Or, The Covntrey Farme. Translated into English by Svrflet, Richard. 1616 http://tei.it.ox.ac.uk/tcp/TextsEPUB/free/A00/A00419.html

(10) \& (11) Featly, Dan. The Grand Sacrilege of The Church of Rome. London, 1630. http:// tei.it.ox.ac.uk/tcp/Texts-HTML/free/A00/A00597.html

(12) Fludd, Robert. Doctor Fludd's Answer vnto M. Foster Or, The Squeesing of Parson Fosters Sponge, ordained by him for the wiping away of the Weapon-Salve. London, 1631. (TREATISE) http://tei.it.ox.ac.uk/tcp/Texts-HTML/free/ A01/A01014.html 
(13) An Address to the Assembly of Pennsylvania, On the Abolition of the Bank of NorthAmerica. Philadelphia, 1785 http://tei.it.ox.ac.uk/tcp/Texts-EPUB/free/N14 /N14900.html

(14) Livy, The Romane Historie written by T. Livius of Padva. Also, the Breviaries of L. Florus: with a Chronologie to the whole Historie: and the Topographie of Rome in old time. Translation by Holland Philemon from Latin, 1600. http://tei.it.ox. ac.uk/tcp/Texts-HTML/free/A06/A06128.html

(15) Dekker, Thomas. The shomakers holiday. Or The gentle craft VVith the humorous life of Simon Eyre, shoomaker, and Lord Maior of London. As it was acted before the Queenes most excellent Maiestie on New-yeares day at night last. London, 1600. http:/ / tei.it.ox.ac.uk/tcp/Texts-EPUB/free/A20/A20083.html

(16) Astell, Mary. Some Reflections upon Marriage, Occasion'd by the Duke E Dutchess of Mazarine's Case; Which is also consider'd. London, 1700. http://tei.it.ox.ac. uk/tcp/Texts-HTML/free/A26/A26097.html

(17) Chudleigh, Mary Lee. The female advocate; or, A plea for the just liberty of the tender sex, and particularly of married women. Being reflections on a late rude and disingenuous discourse, delivered by Mr. John Sprint, in a sermon at a wedding, May 11th, at Sherburn in Dorsetshire, 1699. 1700 http://tei.it.ox.ac.uk/tcp/TextsHTML/free/A32/A32910.html

(18) Fletcher, John. The pilgrim a comedy as it is acted at the Theatre-Royal in Drury-Lane / written originally by Mr. Fletcher and now very much alter'd with several additions ; likewise a prologue, epilogue, dialogue and masque written by the late great poet Mr. Dryden just before his death, being the last of his works. London, 1700. http:/ / tei.it.ox.ac.uk/tcp/Texts-HTML/free/A39/A39808.html

(19) Astell, Mary. Some Reflections upon Marriage, Occasion'd by the Duke E Dutchess of Mazarine's Case; Which is also consider'd. London, 1700. http://tei.it.ox.ac. uk/tcp/Texts-HTML/free/A26/A26097.html

(20) Astell, Mary. Some Reflections upon Marriage, Occasion'd by the Duke \& Dutchess of Mazarine's Case; Which is also consider'd. London, 1700. http://tei.it.ox.ac.uk/ tcp/Texts-HTML/free/A26/A26097.html

\section{References}

Aijmer, Karin (2002). Modal adverbs of certainty and uncertainty in an EnglishSwedish perspective. In Information structure in a cross-linguistic perspective. Brill Online.

Aikhenvald, Alexandra (2011). The grammaticalization of evidentiality. Narrog, Heiko, Bernd Heine, eds. The Handbook of Grammaticalization. Oxford: Oxford University Press, 605-613.

Arppe, Antti, Gilquin Gaëtanelle, Dylan Glynn, Martin Hilpert, Zeschel Arne (2010). Cognitive corpus linguistics: Five points of debate on current theory and methodology. Corpora 2010, 5.1: 1-27.

Beeching, Kate, Ulrich Detges, eds. (2014). Discourse functions at the left and right periphery: Crosslinguistic investigations of language use and language change. Studies in Pragmatics, 12. Retreived from Brill Online.

Benitez-Burraco, Antonio (2017). Grammaticalization and language evolution: Focusing the debate. Language Sciences 63: 60-68. 
Breban, Tine, Jeroen Vanderbiesen, Kristin Davidse, Lieselotte Brems, Tanja Mortelmans (2012). Introduction: New reflections on sources, outcomes, defining features and motivations of grammaticalization. Kristin, Davidse, Tine Breban, Lieselotte Brems, Tanja Mortelmans, eds. Grammaticalization and Language Change: New Reflections. Amsterdam/Philadelphia: John Benjamins, 136.

Brinton, Laurel J. (1996). Pragmatic Markers in English: Grammaticalization and Discourse Function. Berlin: Mouton de Gruyter.

Bromhead, Helen (2009). The Reign of Truth and Faith: Epistemic Expressions in $16^{\text {th }}$ and 17th Century English. Berlin: Mouton de Gruyter.

Cornillie, Bert (2010). On conceptual semantics and discourse functions: The case of Spanish modal adverbs in informal conversation. Review of Cognitive Linguistics 8.2: 300-320.

Cornillie, Bert, Paola Pietrandrea (2012). Modality at work. Cognitive, interactional and textual functions of modal markers. Journal of Pragmatics 44.15: 2109-2226. Retreived from HAL archives ouvertes https://halshs.archives-ouvertes.fr

Culpeper, Jonathan, Merja Kytö (2010). Early Modern English Dialogues: Spoken Interaction as Writing. Cambridge: Cambridge University Press.

de Haan, Ferdinand (2006). Typological approaches to modality. Frawley, William, ed. The Expression of Modality. Berlin: Mouton de Gruyter, 27-70.

Davidse, Kristin, Simon De Wolf, An Van Iinden (2011). The development of (there/it is / I have) no doubt expressing modal and interactional meaning. Journal of Historical Pragmatics 16.1: 25-58. Amsterdam: John Benjamins.

Eckhart, Regine (2002). Semantic change in grammaticalization. Katz, Graham, Sabine Reinhard, Philip Reuter, eds. Sinn \& Bedeutung VI, Proceedings of the Sixth Annual Meeting of the Gesellschaft für Semantik, University of Osnabrück, 53-67.

Eckhart, Regine, Klaus von Heusinger, Christoph Schwarze (2003). Words in Time: Diachronic Semantics from Different Points of View. Berlin: Mouton de Gruyter.

Eckhart, Regine (2011). Semantic reanalysis and language change. Language and Linguistics Compass 5. 1: 33-46.

Fischer, Olga (2008). On analogy as the motivation for grammaticalization. Studies in Language 32: 336-382.

Glynn, Dylan (2014). The many uses of run. Dylan, Glynn, Justyna Robinson, eds. Corpus Methods for Semantics: Quantitative Studies in Polysemy and Synonymy. John Benjamins, 117-144.

Gries, Stefan Th., Anatol Stefanowitsch (2010). Cluster analysis and the identification of collexeme classes. Sally Rice, John Newman, eds. Empirical and Experimental Methods in Cognitive/Functional Research. Stanford, CA: CSLI, 59-72.

Gries, Stefan Th. (2015a). More (old and new) misunderstandings of collostructional analysis: On Schmid and Küchenhoff (2013). Cognitive Linguistics 26.3: 1-31.

Gries, Stefan Th. (2015b). 50-something years of work on collocations. What is or should be next. Sebastian Hoffmann, Bettina Fischer-Starcke, Andrea Sand, eds. Current Issues in Phraseology.John Benjamins, 135-164.

Hennemann, Anja (2012). The epistemic and evidential use of Spanish modal adverbs and verbs of cognitive attitude. Folia Linguistica, 46.1: 133-170.

DOI: http://dx.doi.org/10.1515/flin.2012.5 
Hilpert Martin (2011). Dynamic visualization of language change: Motion charts on the basis of bivariate and multivariate data from diachronic corpora. International Journal of Corpus Linguistics 16.4: 435-461.

Hilpert, Martin (2012). Diachronic collostructional analysis: How to use it and deal with confounding factors. Kathryn, Allan, Justyna A. Robinson, eds. Current Methods in Historical Semantics. Berlin/Boston: de Gruyter, 132-160.

Hilpert, Martin, Stefan Th. Gries (2016). Quantitative approaches to diachronic corpus linguistics. Kytö, Merja, Pahta Päivi, eds. The Cambridge Handbook of English Historical Linguistics. Cambridge: Cambridge University Press, 36-52.

Hopper, Paul J. (1991). On some principles of grammaticalization. Traugott, Elizabeth C., Bernd Heine, eds. Approaches to Grammaticalization I. Amsterdam: John Benjamins, 17-36.

Hopper, Paul J., Elisabeth C. Traugott (2003). Grammaticalization. Cambridge: Cambridge University Press.

Jucker, Andreas H. (2002). Discourse markers in Early Modern English. Watts, Richard, Peter Trudgill, eds. Alternative Histories of English. London: Routledge, 210-239.

Kilgarriff, Adam, Pavel Rychlý, Pavel Smrž, David Tugwell. (2004) ITRI-04-08 the sketch engine. Information Technology, 2004. Retreived from https://www. sketchengine.eu/wpcontent/uploads/The_Sketch_Engine_2004.pdf.

Lehmann, Christian (2002). Thoughts on Grammaticalization. Erfurt: Arbeitspapiere des Seminars für Sprachwissenshaft der Universität Erfurt. https://www. christianlehmann. eu/publ/ASSidUE09.pdf

Lutzky, Ursula (2012). Discourse Markers in Early Modern English. Amsterdam/Philadelphia: John Benjamins.

Montserrat, Gonzàlez, Paolo Roseano, Joan Borràs-Comes, Pilar Prieto (2014). Epistemic and evidential marking in discourse: Effects of register and debatability. Lingua 186: 68-87.

Narrog, Heiko, Bernd Heine (2011). Introduction. The Oxford Handbook of Grammaticalization. Narrog, Heiko, Bernd Heine, eds. Oxford: Oxford University Press.

Narrog, Heiko (2012). Modality, Subjectivity and Semantic Change: A Crosslinguistic Perspective. Oxford: Oxford University Press.

Narrog, Heiko (2017). Three types of subjectivity, three types of intersubjectivity, their dynamicization and synthesis. Olmen, Daniel, Hubert Cuyckens, Lobke Ghesquière, eds. Aspects of Grammaticalization: (Inter)Subjectification and Directionality. Berlin/Boston: Mouton de Gruyter, 18-46.

Nevalainen, Terttu (2006). An Introduction to Early Modern English. Oxford: Oxford University Press.

Nicolle, Steve (2011). Pragmatic aspects of grammaticalization. Narrog, Heiko, Bernd Heine, eds. The Oxford Handbook of Grammaticalization. Oxford: Oxford University Press, 401-412.

Prince, Ellen F., Joel Frader, Charles Bosk (1982). On hedging in physician-physician discourse. Roberto di Pietro, ed. Linguistics and the Professions. Norwood, NJ: Ablex Publishing Corporation, 83-97.

Rissanen, Matti (1999). Syntax. Roger Lass, ed. Cambridge History of the English Language. Vol. III: 1476-1776, 187-331.Cambridge: Cambridge University Press. 
Rychlý, Pavel (2008). A lexicographer-friendly association score. Petr Sojka, Aleš Horák, eds. Proceedings of Recent Advances in Slavonic Natural Language Processing, RASLAN. Masaryk University Brno, 6-10.

Simon-Vandenberger, Anne-Marie (2007). No doubt and related expressions. Hannay, Mike, Gerard Steen, eds. Structural Functional Studies in English Grammar. Amsterdam: John Benjamins, 9-34.

Simon-Vandenberger, Anne-Marie, Karin Aijmer (2007). The Semantic Field of Modal Certainty: A Corpus-Based Study of English Adverbs. Berlin/New York: Mouton de Gruyter.

Traugott, Elisabeth C, Richard Dasher (2002). Regularity in Semantic Change. Cambridge: Cambridge University Press.

Traugott, Elizabeth C. (2003). Constructions in grammaticalization. Joseph, Brian D., Richard D. Janda, eds. The Handbook of Historical Linguistics. Oxford: Blackwell, 624-647.

Traugott, Elizabeth C. (2011). On the Function of Adverbs of Certainty Used at the Periphery of the Clause. Special Lecture at Stanford University. http://pragmatics. gr.jp/content/files/ SIP_013/SIP_13_Traugott.pdf.

Traugott, Elizabeth C. (2012). Intersubjectification and clause periphery. Brems, Lieselotte, Lobke Ghesquière, Freek Van de Velde, eds. Intersections of Intersubjectivity, special issue of English Text Construction 5. 1: 7-28.

Traugott, Elizabeth C. (2014). On the function of the epistemic adverbs Surely and No Doubt at the left and right peripheries of the clause. Beeching, Kate, Ulrich Detges, eds. Discourse Functions at the Left and Right Periphery. Brill Online, 7291.

Wierzbicka, Anna (2006). English: Meaning and Culture. Oxford: Oxford University Press.

Ziegeler, Debra (2011). The grammaticalization of modality. Narrog, Heiko, Bernd Heine, eds. The Oxford Handbook of Grammaticalization. Oxford: Oxford University Press, 595-604.

\section{Author's address}

Chris A. Smith

Associate Professor

Université de Caen Normandie

UFR LVE, MLI bureau 354

14006 CAEN CEDEX

France

Email: chris.smith@unicaen.fr

Received: March 2, 2019

Accepted for publication: June 6, 2019 